\title{
SARTRE: EL RECONOCIMIENTO Y CUIDADO DEL PRÓJIMO COMO PRINCIPIO DE LA ACCIÓN RESPONSABLE
}

Christian A. Rubiano 


\title{
SARTRE: EL RECONOCIMIENTO Y CUIDADO DEL PRÓJIMO COMO PRINCIPIO DE LA ACCIÓN RESPONSABLE ${ }^{\star}$
}

\begin{abstract}
Resumen: El presente texto es una aproximación a la obra de Jean Paul Sartre. El artículo defiende que la teoría de la acción de este autor es indisociable de una teoría moral, según la cual una acción responsable es aquella que reconoce y cuida del prójimo. El texto empieza por brindar una imagen panorámica de ciertos conceptos de la filosofía existencialista sartreana que resultan fundamentales para comprender la dimensión y alcance de la propuesta; acto seguido se presenta una lectura crítica de ciertos pasajes de la obra de Sartre que sustentan la tesis en cuestión.
\end{abstract}

Palabras clave: Sartre, acción, moral, responsabilidad, prójimo.

\section{SARTRE: RECOGNITION AND CARE OF NEIGHBOR AS PRINCIPLE OF RESPONSIBLE ACTION}

\begin{abstract}
The present paper is an approach to Jean Paul Sartre's work. The article defends that the Action Theory of this author it's inseparable from a Moral Theory, therefore a responsible action is one that recognizes and care for others. The text begins by providing an overwiew of certain concepts of Sartre's existentialist philosophy that are fundamental to understand the magnitude and scope of the proposal; then a critical reading of some passages in Sartre's work it's presented to supports the thesis.
\end{abstract}

Keywords: Sartre, action, moral, responsibility, neighbor.

Fecha de recepción: junio 16 de 2015

Fecha de aceptación: septiembre 22 de 2015

Forma de citar: Rubiano, C. (2015). "Sartre: El reconocimiento y cuidado del prójimo como principio de la acción responsable". Revista Filosofía UIS. 15 (2). pp. 141-165.

Christian A. Rubiano: colombiano. Filósofo y estudiante de la Maestría en Filosofía de la Universidad del Rosario y profesor de la misma Universidad.

Correo electrónico: christian.rubiano@urosario.edu.co

* Artículo de revisión de tema 


\section{SARTRE: EL RECONOCIMIENTO Y CUIDADO DEL PRÓJIMO COMO PRINCIPIO DE LA ACCIÓN RESPONSABLE'}

Un hombre no es, tan solo, lo que es en un determinado momento. Siempre somos más de lo que ahora somos. Cuando se afirma que el ser es tiempo, no se quiere decir que el ser es lo que es en el instante de su enunciación. Se quiere decir que el ser es lo que es ahora, lo que ha sido y lo que aún no es. Un hombre siempre es el ser y la nada².

Si no somos deterministas ${ }^{3}$ bien podemos afirmar que existe una asimetría entre el pasado y el futuro, en tanto que el primero está cerrado mientras que el último se encuentra abierto, pero no podemos suponer naturalezas radicalmente excluyentes entre ambos modos de la temporalidad. Al menos un rasgo les es común: tanto el pasado como el futuro son nada. Ambos, desde el ahora, no constituyen más que ausencias. Pero esto no implica que no sean, en el presente, de cierto modo. El presente entraña ambos modos de la temporalidad. El pasado

\footnotetext{
${ }^{1}$ El artículo surge en el marco de la investigación adelantada, desde el primer semestre del 2014 al primer semestre de 2015, por el semillero de identidad narrativa y sufrimiento del grupo en Ética aplicada, trabajo y responsabilidad social de la Universidad del Rosario.

${ }^{2}$ El ser y la nada de Jean P. Sartre. En particular el cuarto acápite (La concepción fenomenológica de la Nada) en el primer capítulo de la primera parte (El problema de la nada). "Es verdad que se puede concebir de otra manera la complementariedad del ser y la nada. Se puede ver en uno y en otra dos componentes igualmente necesarios de lo real [...] Lo real sería, en cierto modo, la tensión resultante de esas fuerzas antagónicas. Hacia esta nueva concepción se orienta Heidegger (¿Qué es metafísica?)" (Sartre, 2008, p. 58).

${ }^{3}$ El universo abierto de Karl R Popper, en particular el primer acápite (Determinismo: Religioso, "científico" y metafísico) del primer capítulo, "la idea intuitiva de determinismo puede resumirse diciendo que el mundo es como una película de cine: la fotografía o la escena que está proyectándose es el presente. Las partes de la película que ya se han proyectado constituyen el pasado. Y las que aún no se han proyectado constituyen el futuro. En la película, el futuro coexiste con el pasado; y el futuro está fijado, exactamente, en el mismo sentido que el pasado. Aunque el espectador no conozca el pasado, todo suceso futuro, sin excepción, podría en principio conocerse con certeza, exactamente como el pasado, puesto que existe en el mismo sentido que existe el pasado" (Popper, 1986, p. 29).
} 
siempre está en el presente como historia; el futuro, por su parte, siempre está disponible como posibilidad. Al primero lo trae la memoria, al segundo lo contempla la imaginación. Ambas modalidades del tiempo son accesibles desde el presente como imágenes.

Esto no es más que otra manera de señalar que en todo instante estamos en capacidad de ver tanto el ayer como el mañana. Empero, la posibilidad de remembranza y figuración no es lo que explica el vínculo entre ambos instantes. La conjunción de presente y futuro sólo es posible a través de la acción. Esto no quiere decir, por supuesto, que allí donde no se da el tipo de eventos que podemos llamar acciones, por ejemplo, en la historia natural, se rompa la conexión temporal. Lo que ocurre es que sólo hablamos de una tal conexión en virtud de unas categorías propias de determinado ente (nosotros mismos). El tiempo no está en la naturaleza, el tiempo está en los hombres. La roca, la planta, los animales no tienen una historia. El problema no es acá el de la existencia del mundo exterior, sino el de la historia de ese mundo. Tales fenómenos sólo obtienen una historia en virtud de un acto humano. Quedan insertos en la temporalidad, por ejemplo, tras una enunciación o un uso. Y es que el tiempo, como concepto, no les es propio.

El vínculo entre pasado y futuro es lo que la filosofía existencialista llama la estructura del acto existencial ${ }^{4}$. Se trata de eventos en los cuales, intencionalmente, vinculamos el pasado con el futuro. En este artículo quisiera defender que todo lo que podemos llamar acciones son actos de esa naturaleza. Una teoría similar fue la desarrollada por Anscombe en su célebre texto Intención (1991). El problema con el enfoque de la autora es que para ella el problema de la intención es independiente del problema de la responsabilidad ${ }^{5}$ (del problema moral). Para la teoría de la acción existencialista que aquí me propongo exponer ambas instancias son indisociables. No se puede hablar de acciones sin hablar al tiempo de problemas morales. Es en este punto, y en sus consecuencias, donde reside la riqueza de la teoría. Ahora, no es que tal vínculo indisoluble sea una idea particularmente original de Sartre (o de otros existencialistas), pero estimo que la naturaleza de la conjunción sí lo es.

\footnotetext{
${ }^{4}$ Introducción al Existencialismo de Nicola Abbagnano. En particular el tercer acápite (La existencia sobre el fundamento de la indeterminación problemática) del primer capítulo (La filosofía como existencia). "Pero en el acto existencial es este movimiento, que unifica pasado y porvenir en el presente de la decisión y que constituye, en el porvenir, una situación que puede no ser, pero que debe ser, el fundamento y la justificación de la situación que ha sido. Este movimiento propio del acto existencial auténtico, esta soldadura de una situación futura que se presenta indeterminada en su posibilidad, pero que, sin embargo, debe ser, con una situación inicial, puede llamarse estructura" (Abbagnano, 1997, p. 18).

${ }^{5}$ Intención. En particular la sección 25. Comentarios a propósito del hombre que bombea agua envenenada a un edificio sin tener la intención de asesinar a sus ocupantes (Anscombe, 1991, p. 91-96).
} 
Con el propósito de exponer las consecuencias de esta idea, empezaré (I) por brindar una imagen panorámica sobre la filosofía existencialista sartreana, de suerte que el lector pueda familiarizarse con las propuestas y conceptos que permitirán (II) comprender por qué una acción responsable es aquella que reconoce y cuida al prójimo. Por razones pedagógicas para este texto recurrí a la conferencia El existencialismo es un humanismo, dictada por Sartre en 1946, como punto de acceso a los problemas centrales de la doctrina. Sin embargo, el conjunto de la reflexión se sustenta en la lectura crítica de El ser y la Nada.

\section{1. "Toda verdad y toda acción implican un medio y una subjetividad" (Sartre, 2006, p. 10)}

Toda verdad se da en un medio que le brinda su validez. Esto es otra manera de decir que el criterio de verdad o falsedad de un enunciado depende del marco en el cual se enuncia (una red de significados). Si la verdad no es independiente del contexto, lo que está en juego es la historicidad de la verdad. ¿Qué quiere decir que la verdad implique una subjetividad humana? Se trata, primero, de la afirmación según la cual toda verdad supone un sujeto que la enuncia; y segundo, que la validez del enunciado no es independiente del sujeto enunciador. Verdad y poder son instancias indisociables.

La acción, dice Sartre, implica un medio. Decir que una acción se desarrolla en un espacio-tiempo no dice mucho. Parece que el término medio en este caso también se usa en un sentido teleológico (medio para un fin). Si decimos que una acción implica un medio queremos decir que se trata de un evento que se realiza para algo más. Cuando afirmamos que $\mathrm{A}$ actúa lo que mentamos es que "A hace $x$ para hacer (u obtener) $y^{\prime \prime}$.

Lo descrito es lo que podríamos llamar una acción mediática. Empero, quizá no es esto a lo que necesariamente se refiere Sartre. Otra interpretación posible es que toda acción supone un medio que le sirve de desencadenante. ¿Cuál podría ser ese medio? Se trataría de la subjetividad humana. Una acción sería un evento en la vida de un agente cuyo desencadenante es el agente mismo. Esto no debe pasar desapercibido. Si tenemos razón, lo que Sartre estaría diciendo es que una acción no puede leerse como una consecuencia necesaria dentro de una serie causal de eventos físicos.

El origen de la acción no es una causa física precedente en el tiempo, sino una subjetividad humana. ¿Se puede leer tal subjetividad como un tipo de causa? Sí, pero ha de ser un tipo de causa diferente a la causa física, una causa que no 
instancie leyes ${ }^{6}$. Se trataría de una causalidad por libertad. Así las cosas lo que hace el existencialismo es reconocer en los hombres la posibilidad de elección. No hemos hecho otra cosa que insertarnos en la antinomia kantiana ${ }^{7}$. ¿Acaso la solución de Sartre es de tipo compatibilista ${ }^{8}$ como parece ser la kantiana? ¿La libertad sartreana es libertad trascendental?

Según lo dicho, desde el marco de la filosofía existencial, una acción constituye un evento originado por la subjetividad de un agente. Dicho evento es susceptible de ser capturado con un enunciado de la forma "A está haciendo x para hacer (u obtener) $y^{\prime \prime}$. ¿Pero qué es lo que hay en la subjetividad humana con el poder de originar una acción?

\section{2. "Lo que tienen en común (las posturas existencialistas) es simplemente que consideran que la existencia precede a la esencia, o si se prefiere, que hay que partir de la subjetividad" (Sartre, 2006, p. 11)}

En el ámbito de una filosofía esencialista, una doctrina que afirme que la esencia precede a la existencia, lo que encontramos es que toda posibilidad existencial está determinada por el ser. La experiencia posible del hombre no será más que lo que la esencia humana permita que sea. Lo que hace el existencialismo es un giro copernicano. Ahora es la experiencia la que determina el ser. ¿Esto quiere decir que el hombre empieza por ser algo y luego modifica lo que es? No exactamente. Lo que se está afirmando es que el hombre, su esencia, empieza por ser nada y poco a poco va construyendo lo que es. El en-sí siempre es un para-sí. La esencia es la serie de nuestras acciones.

\footnotetext{
${ }^{6}$ Se trataría, entonces, de una causa anómala. O quizá de un enunciado que tiene la forma de una ley "Si X entonces Y", pero que no es legaliforme. Podría tratarse de una causa mental (una razón) que no supone necesidad en la conjunción con un evento físico. Una idea similar es la desarrollada por Davidson en su teoría de la acción. Ensayos sobre acciones y sucesos. En particular los ensayos "Sucesos mentales" (1968-1969), "Acciones, razones, causas" (1963) y "Libertad para actuar" (1973).

${ }^{7}$ Hablo de la tercera antinomia de la Crítica de la razón pura: "Tesis: La causalidad según leyes de la naturaleza no es la única de la que pueden derivar todos los fenómenos del mundo. Para explicar estos nos hace falta otra causalidad por libertad. Antítesis: No hay libertad. Todo cuanto sucede en el mundo se desarrolla exclusivamente según leyes de la naturaleza" (Kant, 1978, p. 299).

${ }^{8}$ El idealismo trascendental de Kant (1992) de Henry Allison. El carácter empírico e inteligible de las acciones humanas de Camila de Gamboa. "Kant, mediante la distinción entre fenómenos y noúmenos, considera que la libertad trascendental es compatible con la ley de causalidad. Esta tesis, como observa Henry E. Allison, constituye una postura compatibilista que permite explicar una misma acción humana desde dos diferentes perspectivas: la libertad y la necesidad" (De Gamboa, 2005, p. 84).

${ }^{9}$ Esto no quiere decir que se trate de una creación ex nihilo. La esencia empieza por ser nada pero no parte de la nada. Se construye sobre el trasfondo de la corporalidad y de la historia, pero tales bases no son los determinantes últimos del carácter de la construcción, tan solo su soporte.
} 
¿En virtud de qué se da tal construcción? Pues bien, lo que determina lo que somos son nuestras acciones. Lo que quiere decir Sartre es que al ir eligiendo nos vamos eligiendo a nosotros mismos. Si esto es correcto ello implica que una acción no puede ser determinada. La acción siempre es determinante. ¿Cuál es el objeto de su determinación? El ser, su sentido. Ello en un trasfondo ontológico, en el marco de lo óntico lo que diríamos es que la acción es el determinante del sentido de la vida. Las acciones son las determinantes del sentido del mundo y estas, siguiendo lo expuesto anteriormente, serían el fruto de una subjetividad humana.

No es que se destruya la idea de una esencia humana, lo que ocurre es que su contenido ha sido transformado. Ésta ya no es el fundamento de determinación de toda posibilidad, ahora es el resultado de las acciones de una subjetividad. Del sujeto trascendental kantiano se ha pasado al sujeto existencial. Para este sujeto la acción precede a toda definición y ello implica que el hombre sería "un ser que existe antes de poder ser definido por ningún concepto (Sartre, 2006, p. 10)".

\section{3. "El hombre es el único que no sólo es tal como él se concibe, sino tal como él se quiere" (Sartre, 2006, p. 13)}

Hemos dicho que la manera en que el hombre configura su ser es a través de la acción. Si decimos que el hombre se hace tal como se quiere, lo que estamos diciendo es que las acciones siempre manifiestan un querer. Empero, zacaso no solemos decir cosas como "lo hice sin querer, fue un accidente"? Sin duda, pero tales enunciados están fundados sobre un equívoco. Según tal idea las acciones pertenecerían al conjunto de los eventos en la historia de un sujeto y se dividirían en dos clases: acciones queridas y acciones no queridas. Las primeras serían eventos en los que el sujeto de la acción es un agente. Las segundas eventos en los que el sujeto de la acción es un paciente. El querer siempre es un intencionar, en consecuencia la distinción no es otra que la célebre: acciones intencionales y acciones no intencionales: distinción errada.

Cuando un hombre que camina distraído tropieza con un bache y cae, no diremos que su caída es una acción intencional. Pero tampoco diremos que es una acción no intencional. Este sujeto no ha actuado, ha sufrido un accidente. La caída no es la manifestación de un intencionar puesto que no está proyectada hacia un porvenir. No es que la caída no afecte el futuro del agente, lo que ocurre es que dicha afectación del sentido no ha sido la manifestación de un querer. "Conviene observar ante todo, en efecto, que una acción es, por principio, intencional. El fumador torpe que por descuido ha hecho estallar un santabárbara, no ha actuado" (Sartre, 2008, p. 591). No existe algo como las acciones no intencionales, a lo sumo acciones cuyo contenido no es grato y en las cuales los agentes, para huir de la responsabilidad del contenido, niegan la intención del acto. Es lo que Sartre llama actos de mala fe. 
Una acción es un evento donde se juega el querer ¿Cómo podemos reconocer este tipo de eventos? En otras palabras icómo podemos reconocer la intención? Sartre no es muy claro en ello. Sin embargo, si seguimos a Anscombe $(1991)^{10}$ podemos hallar ciertas luces: una acción intencional es susceptible de ser identificada en virtud de la respuesta que ofrece el agente de la acción ante la pregunta ¿Por qué hiciste $X ?^{11} \mathrm{Si}$ a tal pregunta el agente responde aduciendo a una causa menta/12, o bien ubicando el evento dentro de un plan mayor ${ }^{13}$, entonces podemos afirmar que dicho evento es una acción [intencional]. No hay otro modo, pues la intención es un conocimiento no observaciona ${ }^{14}$ y nunca tenemos un acceso privilegiado a la mente del otro.

Veamos que el caso de la caída no se puede responder (sinceramente ${ }^{15}$ ) en estos términos. Ante la pregunta por qué te caíste, el agente respondería cosas como: "porque perdí el equilibrio", "porque tropecé con un bache". En ninguno de los dos casos se aduce a una causa mental ni se coloca el evento dentro de un plan mayor. Cosa diferente si el agente fuera, por ejemplo, un futbolista y ante la misma pregunta nos respondiera algo como "me caí para que pitaran una falta". En este caso sí hay causa mental (quiero que piten la falta) y ubicación dentro de un plan mayor (me caigo para que piten la falta).

\footnotetext{
${ }^{10}$ Lo vuelvo a decir: dejando de lado el problema de lo moral, el análisis de Anscombe sobre la acción es equiparable al realizado por Sartre.

${ }^{11}$ Intención, en particular el quinto acápite. "¿Qué distingue a las acciones intencionales de las que no lo son? La respuesta que voy a sugerir consiste en que aquéllas comprenden las acciones en las cuales resulta aplicable alguno de los sentidos de la pregunta "¿Por qué?"; desde luego, el sentido al que nos referimos es el que presenta en su respuesta, de ser positiva, una razón para actuar" (Anscombe, 1991, p. 51).

12 Intención, en particular el décimo acápite. "Llamaré al tipo de causa en cuestión una "causa mental". Las causas mentales son posibles no sólo para las acciones ("La música marcial me apasiona, por eso camino de un lado a otro"), sino también para sensaciones e incluso pensamientos" (Anscombe, 1991, p. 59).

${ }^{13}$ Intención, en particular el undécimo acápite. "Podría pensarse que cuando se responde a la pregunta "¿Por qué?", presentando la intención con que actúa una persona, por ejemplo, con la mención de un hecho futuro, también se trata de una causa mental, pues, ¿ $N o$ podría acaso replantearse la respuesta según la forma : "porque quería..." o "debido al deseo de..."?" (Anscombe, 1991, p. 60).

${ }^{14}$ Intención, en particular el octavo y vigésimo octavo acápite. "La clase de cosas conocidas sin observación es de interés general para nuestro estudio porque las acciones intencionales constituyen una subclase de ella" (Anscombe, 1991, p. 57).

${ }^{15}$ Cuando me caigo de la silla, y no he tenido la intención de hacerlo, si me preguntan el ¿por qué? de la acción yo no diré cosas como "porque quiero ir al médico para que me revise un hematoma" o "para saber qué se siente que a uno le pregunten por qué se cayó". Yo no diré estas cosas (al menos como una respuesta sincera), si las digo será claro que es un sarcasmo ya que la pregunta ipor qué?, en estas circunstancias, no resulta aplicable (en el sentido que nos interesa) puesto que no hay un interés futuro de mi parte en el evento que me ha acontecido.
} 


\section{4. "El hombre será, ante todo, lo que habrá proyectado ser. No lo que querrá ser" (Sartre, 2006, p. 13)}

Hemos dicho que la acción es lo que determina el sentido del ser. Así mismo, que toda acción siempre entraña un querer (una intencionalidad) y que, en consecuencia, el hombre se hace como se quiere. Ahora Sartre nos dice que el hombre será lo que habrá proyectado ser y no lo que querrá ser. Pero żacaso el ser no se hace como se quiere? ¿Entraña la reflexión sartreana una contradicción? En lo absoluto, esto no es más que una contradicción aparente. Para comprender lo que dice Sartre hay que entender un concepto sutil: el querer querido.

En ¿Qué es la ilustración? Kant (1985) distingue entre dos usos de la razón: el uso privado y el uso público. Este último es el uso libre de la razón en espacios de deliberación pública. El primero refiere al uso de la razón que debe manejar un funcionario, o alguien que hace las labores de otro (irazonad, pero obedeced!). Si analizamos la acción de un funcionario, que acepta la propuesta kantiana y no está de acuerdo con lo que debe hacer, podríamos afirmar que dicha persona actúa intencionalmente (cumple la orden), pero que el contenido de la acción no le es grato y va contra su razón. Lo que está en juego son dos conceptos de querer.

El querer puede ser un intencionar, así mismo puede ser una carga afectiva. Cada sentido del término es completamente independiente del otro. Yo puedo querer algo (en el sentido de intencionarlo), y aun así no quererlo afectivamente. También puedo querer algo afectivamente y nunca intencionarlo. Se trata de aquellas cosas que hacemos, aunque no las queramos hacer, porque debemos hacerlas. O de aquellas otras que aun queriéndolas nunca las hacemos. En tal dialéctica de la acción lo que tenemos es que toda acción es un querer, pero no necesariamente que el contenido de toda acción realizada es algo querido. Hay, entonces, tanto quereres no queridos como quereres queridos.

Cuando Sartre dice que el hombre será lo que habrá proyectado ser y no lo que querrá ser, está pensando en un caso de querer no querido: acciones realizadas por el agente (con intención) pero cuyo contenido no le es grato. Esto es una manera de señalar que la acción sólo será una acción comprometida cuando la afectividad entre en concordancia con el intencionar.

Se trata, así mismo, de una manera sutil de enunciar la naturaleza de la respuesta que se ofrece ante la pregunta por el sentido del ser: la respuesta no es verbal o psicológica, sino performativa. Un hombre no es lo que quiso ser (afectividad), sino lo que hizo. Empero, eso no implica que lo hecho no fuera un querer de cierta naturaleza (un intencionar). Siempre nos hacemos como queremos aunque no queramos lo que hacemos de nosotros. Decir que no nos hacemos como queremos porque no queremos lo que hacemos de nosotros es lo que el existencialismo llamará actuar de mala fe. 
1.5. "El primer paso del existencialismo es poner a todo hombre en posesión de lo que es, y asentar sobre él la responsabilidad total de su existencia. $Y$ cuando decimos que el hombre es responsable de sí mismo, no queremos decir que el hombre es responsable de su estricta individualidad, sino que es responsable de todos los hombres" (Sartre, 2006, p. 13)

Cuando decíamos que toda acción estaba fundada en la intencionalidad, mentábamos un querer como la causa mental de la acción. Habrá que afinar tal afirmación. Y es que la causa mental que desencadena la acción no es la verdadera causa de esta, puesto que tal causa mental remite a una causa no causada. Se trata de la libertad. La base sobre la cual se asienta la acción humana no es, propiamente, la causa mental del agente, sino una originaria libertad del sujeto. No actuamos intencionalmente porque nuestras acciones remitan a causas mentales, sino porque somos libres. Actuamos, no porque podamos instanciar un querer, sino porque ejercemos la libertad. De otro modo: la posibilidad de instanciar un querer tiene como condición previa la realidad de una inalienable libertad.

¿Constituye la libertad el axioma del cual se deriva el existencialismo? O, más bien, ¿es un teorema de la teoría, una conclusión de otros principios? Me siento inclinado a tomar este segundo camino. La libertad existencial no es un principio sino el resultado de la muerte de Dios. Somos libres porque Dios no existe. Como no hay un Dios para concebir la naturaleza humana el hombre se encuentra, en consecuencia, en una originaria condición de apertura. El ser hará de sí lo que quiera hacer porque no hay una esencia que lo determine a ser algo.

Poner a un hombre en posesión de lo que es quiere decir hacerlo tomar las riendas de sus acciones. No es que en algún momento la acción no sea del agente y que el existencialismo quiera devolverle al sujeto el control sobre ellas. La toma de posesión es una toma de conciencia. Entregarle al hombre el hombre es hacerlo consiente que es él, gracias a su libertad, la razón de lo que es. Pero si la acción se funda sobre la libertad, dicha posesión es la asunción o el reconocimiento de la libertad originaria. Poseernos es ser conscientes de nuestra libertad.

¿Qué implica que un hombre reconozca su libertad? Pues bien, eso no quiere decir-tan solo- que el hombre declarará que siempre que actúa lo hace libremente; significa, también que el hombre debe declararse responsable por todos sus actos y por las consecuencias de estos. Vale la pena destacar que la responsabilidad, bajo el enfoque existencial, no deriva de la intención sino de la libertad. Esto no debe pasar desapercibido, pues tal es el paso que permite conectar el problema de la acción con el de la moral. Y es que de la intención, puesto que tal no excluye el determinismo, no se puede derivar la responsabilidad. Por ello Anscombe 
(1991), siguiendo a Wittgenstein, no llega a conclusiones morales en su teoría de la acción.

Para ilustrar este punto valgámonos de la metáfora de Wittgenstein que Anscombe relata. "Una vez leí unas notas sobre una conferencia de Wittgenstein, en la cual él imaginaba algunas hojas arrastradas por el viento que, conforme éste las empujaba, decían: < <Ahora iré en esta dirección... Ahora iré en aquella >> " (Anscombe, 1991, p. 48). ¿Qué quería decir el filósofo austriaco con este enunciado? Al parecer se trata de una negación del libre albedrío. Empero, no es la simple negación de la libertad sino la demostración de que ello no implica, necesariamente, la negación de la intención. Un sujeto puede tener intenciones y ello no implica que sea libre, finalmente tal intención puede ser un resultado necesario en la cadena causal.

Así las cosas, difícilmente se podrán realizar juicios morales pues no tenemos razones para pensar que, porque un agente tenga intenciones, pudo haberlas configurado de manera diferente y actuar de otra manera. En conclusión: la intención no es un buen fundamento para la responsabilidad puesto que no excluye la posibilidad del determinismo. Para que podamos declarar responsable a un sujeto por su acto este ha de haber tenido, en un instante previo a la acción, la posibilidad de haber actuado de otra manera. Ya vimos que la mera intención no satisface esta condición. Pero sí lo hace la libertad. Si es cierto, como he defendido, que el fundamento de la acción es la libertad entonces el problema moral se hace accesible. Es porque somos libres que debemos declararnos responsables, pues la libertad supone que siempre podemos actuar de manera distinta a como lo hacemos.

Habrá que notar, sin embargo, que libertad y responsabilidad no son, según la doctrina existencial, instancias disociadas. Es decir, yo no puedo ser libre y no ser responsable. Puedo, por supuesto, no asumir mi responsabilidad en un plano óntico, pero ontológicamente siempre lo seré ${ }^{16}$.Poner al hombre en posesión de sí es, según lo expuesto, hacerlo consiente de la responsabilidad. Pero no se trata, argumentará Sartre, de una responsabilidad individual sino absoluta. En virtud de nuestra libertad somos responsables del mundo entero. ¿Cómo es esto posible? ¿Por qué asumir un tal compromiso?

Parece que en la acción no solo se juega el destino particular del sujeto que actúa, sino también una imagen normativa. Cada vez que actuamos, junto con el acto, surge una imagen reflejo del acto que afirma que todo sujeto debería llevar a

\footnotetext{
${ }^{16}$ Si hay un absoluto en el existencialismo, como bien percibe Adorno en la Introducción a Dialéctica negativa, es esta idea de libertad y responsabilidad. "A pesar de su extremo nominalismo, la filosofía de Sartre se estructuró en su fase más influyente según la antigua categoría idealista de la libre acción del sujeto" (Adorno, 1984, p. 55).
} 
cabo una acción de la misma naturaleza. Actuar es legitimar el contenido del acto y promoverlo. Y es que toda acción no solo tiene un significado para el agente, sino que también es símbolo para sus espectadores:

Elegir ser esto o aquello, es afirmar al tiempo el valor de lo que elegimos, porque nunca podemos elegir mal; lo que elegimos es siempre el bien, y nada puede ser bueno para nosotros sin serlo para todos. Si, por otra parte, la existencia precede a la esencia y nosotros quisiéramos existir al mismo tiempo que modelamos nuestra imagen, esta imagen es valedera para todos y para nuestra época entera. Así, nuestra responsabilidad es mucho mayor de lo que podríamos suponer, porque compromete a la humanidad entera (Sartre, 2006, p. 14).

Cuando actuamos somos responsables del mundo entero ya que la acción entraña en sí la alteridad. La acción, hemos señalado, siempre remite a un porvenir; así mismo, pone en consideración al pasado. Esto significa, primero, que la acción no está limitada al instante presente en el que se actúa; segundo, que la acción sólo tiene sentido en una red de significado temporal.

Esta última consideración es importante, eso quiere decir que uno no actúa porque sí, sino porque está inserto en un mundo. Pero mundo no debe entenderse como naturaleza. Se trata de un término que mienta un concepto absolutamente humano. Las cosas están en la naturaleza; el hombre, por su parte, está en el mundo. Mundo es una red de proposiciones, relaciones, prácticas, labores, aspiraciones, deseos, etc. que los hombres han configurado. Así las cosas, cuando decimos que el hombre actúa podemos decir que lo hace porque vive con otros hombres en un mundo. En otras palabras: el hombre actúa porque se encuentra en situación.

Dado que el actuar se da en el marco del mundo, la conciencia de la acción es en consecuencia, no solo conciencia de la libertad, sino también conciencia de la manera en que afectamos al mundo. Conciencia de la situación, esto es, de la manera en que afectamos a los hombres que, junto a nosotros, comparten el mundo que habitamos.

Cada vez que actuamos, irremediablemente, afectamos a los otros que están en el mundo, bien sea porque nuestra acción los interpela directamente, bien sea porque les aparece como símbolo. En dicho panorama el hombre consciente es aquel que considera a esos otros que afecta en el actuar. ¿Pero de qué tipo es dicha consideración?

Se trata de un ejercicio de reflexión: debo pensar cómo afecta lo que hago a la totalidad de los hombres que junto a mí comparten el mundo en el que habito. Es una idea equiparable a la postulada por Kant en la primera formulación del imperativo categórico: obra de forma tal que tu acción sea susceptible de 
ser universalizada. Eso es la responsabilidad. Si uno es consciente de sí, esto es (según lo dicho) ser consciente de sus acciones, entonces debe preguntarse qué ocurriría si todos actuaran de la manera en que yo lo hago. Es la respuesta a esta pregunta la que determina el carácter moral de la acción. Lo que hace Sartre, al poner de manifiesto que la alteridad está implícita en el actuar, es juntar la teoría de la acción con la teoría ética. A continuación expondré las consecuencias de tal conjunción.

II

La acción está fundada sobre la libertad. Eso implica que el hombre es responsable por todas sus acciones. Dicha responsabilidad no es particular sino absoluta. Ser libre es ser responsable. Estos principios, de ser asumidos con entereza y coraje por los agentes, llevan al compromiso existencial. Pero toda asunción es una posibilidad, de suerte que la responsabilidad aunque ontológicamente inalienable, ónticamente siempre constituye un poder ser. Un hombre siempre es responsable por lo que es, pero asumir tal responsabilidad en el mundo de la vida es una opción (tal es la libertad); y es que el compromiso no es el modo más propio del ser del hombre. Antes bien la existencia media se desenvuelve en una continua negación del compromiso bajo la figura del Uno.

Se trata de un estado caracterizado porque el "quién es cualquiera, es uno" (Heidegger, 2008, p. 143). Un existir donde el sujeto de la acción niega su carácter de agente y hace de sí el objeto con el cual otros consolidan su poder. Un transitar cuyo trazado está premeditado por el juicio que los otros imponen sobre el sujeto. Existencia que, desembozada de la dirección subjetiva, se encauzada en las líneas del destino divino, social e histórico.

El existenciario más propio de este ser medio del hombre es lo que Heidegger ha llamado las habladurías, esto es, un comprender e interpretar ajeno al sujeto enunciador que, sin embargo, es el molde de todas sus apropiaciones o juicios: el hombre hace lo que los demás hacen, lee lo que los demás leen, dice lo que los demás dicen, etc. Lo que hay en tal manera de guiar la acción y el discurso, y que a su vez constituye la naturaleza del Uno, es un abandono del propio juicio como resultado de la no asunción de la libertad. Cuando un hombre se piensa determinado por su momento histórico o bien por el mandato divino, su acción y pensamiento no desarrollan voz propia sino que se limitan a tomar como suyos el pensamiento y actuar de los otros. Con ello surgen los arquetipos existenciales y los sujetos se declaran hijos de su época o víctimas de las circunstancias. Lo que se esconde tras este modo de reconocimiento del propio ser es la no asunción de la responsabilidad como resultado de la negación de la libertad. Es lo que Sartre Ilama mala fe. 
2.1. "Ante todo se puede juzgar (y este no es un juicio de valor, sino un juicio lógico) que ciertas elecciones están fundadas en el error y otras en la verdad. Se puede juzgar a un hombre diciendo que es de mala fe. si hemos definido la situación del hombre como una elección libre, sin excusas y sin ayuda, todo hombre que se refugia detrás de la excusa de sus pasiones, todo hombre que inventa un determinismo, es un hombre de mala fe" (Sartre, 2006 (1946), pág. 28)

¿Cómo es posible que una elección esté fundada en el error? Se trataría de situaciones en las cuales el sujeto de la acción concibe erróneamente el fundamento de la misma. No se está hablando aquí de la toma de malas elecciones (malas decisiones), sino del inadecuado reconocimiento de qué es lo que posibilita una elección. El juicio de mala fe es lógico, no moral o estético. Ante la pregunta, ¿Por qué hiciste $X$ ? el agente, en un plano óntico, puede aducir (de tratarse realmente de una acción) a una causa mental o a la explicitación del evento dentro de un plan mayor. Lo que es necesario identificar es a qué refiere la respuesta en un plano ontológico. Si toda elección está fundada en la libertad, como hemos defendido hasta el momento, entonces cualquier respuesta que, en un plano ontológico, apunte a algún tipo de determinismo caería en el error. Una tal respuesta sería la que para el existencialista constituiría un enunciado de mala fe.

El hombre, señala Sartre, "no solamente es el ser por el cual se develan negatidades en el mundo; es también aquel que puede tomar actitudes negativas respecto de sí" (Sartre, 2008 (1943), pág. 95). Esto significa que el hombre puede poner de manifiesto lo que el mundo no es y, así mismo, presentarse y reconocerse como no es. Develar la negatidad del mundo quiere decir poner de manifiesto la nada, o las posibilidades de sentido que el mundo tiene. Empero, no se trata de una labor profética sino comprensiva. Cuando el hombre comprende las condiciones del presente, entonces está en capacidad de figurar los posibles caminos del futuro. Solo cuando se comprende la opresión de los obreros, se piensa la posibilidad de una revolución. De manera similar, la toma de actitudes negativas respecto de sí supone un conocimiento de lo que se es. Y es que no puede surgir una negación sin tener claro qué es lo que se niega.

La mala fe es un tipo de actitud negativa respecto de sí. ¿Qué es lo que niega este fenómeno? Pues bien, se trata de la negación de la libertad de los agentes. Ahora, lo que no debe pasar desapercibido es que una tal negación supone el conocimiento de la libertad, de suerte que ha de tratarse de un fenómeno con fines particulares. ¿Por qué un agente quisiera negar su libertad?

La mala fe no es, valga aclarar, la capacidad ontológica de rechazar la condena a la libertad, sino la posibilidad óntica para que los otros nos reconozcan como determinados. ¿Por qué un hombre quisiera presentarse ante los otros hombres 
como si careciera de libertad? Sin duda, para que sus acciones fuesen reconocidas como el resultado necesario de una serie causal y, en consecuencia, como inevitables. Cuando un hombre niega su libertad lo que trata de hacer es eludir la responsabilidad que le imponen sus actos. Y es que la responsabilidad no es compatible con el determinismo físico (el compatibilismo no se puede tomar en serio). Así las cosas, la mala fe constituiría un fenómeno intencional. Pero esto no quiere decir que se trate de un fenómeno consiente, pues la mala fe, aunque se asimila a la mentira, en realidad es un autoengaño.

A menudo se la asimila a la mentira. Se dice indiferentemente de una persona que da pruebas de mala fe o que se miente a sí misma. Aceptaremos que la mala fe sea mentirse a sí mismo, a condición de distinguir inmediatamente el mentirse a sí mismo de la mentira a secas (Sartre, 2008, p. 96).

La mentira siempre supone otro al cual le miento. Para el mentiroso lo que está en juego es el encubrimiento de una verdad que él conoce. La mentira que se enuncia es algo que el mentiroso sabe, con plena certeza, que es falsa. Si el otro cree en el enunciado falso, que el mentiroso le presenta, entonces la mentira se ha concretado e inicia una dialéctica de engañado y engañador. Si la mala fe es un mentirse a sí mismo, entonces el sujeto que actúa de mala fe es tanto engañado como engañador. Esto implicaría que el sujeto de mala fe conoce la verdad y a su vez cree en la mentira.

Un tal fenómeno supondría que el agente cree tanto en el enunciado verdadero $(\mathrm{P})$ como en su contradicción $(-\mathrm{P})$. El sujeto sabe que se está mintiendo y -a pesar de ello- cree su mentira. Para sostener una tal dialéctica sería necesario que la conciencia fuera dual y una parte de ella engañara mientras que la otra es engañada. Se requeriría de una idea sobre lo mental como la de Freud, sin embargo para Sartre la conciencia es unitaria ${ }^{17}$.

¿Si Sartre tiene razón y la conciencia es unitaria (esto aún está en debate en la actualidad) cómo puede un hombre auto engañarse? Pues bien, lo que ocurre es que el hombre empieza conociendo la verdad y desea encubrírsela. Cuando logra su cometido pierde conciencia de la verdad. La mala fe es un fenómeno

\footnotetext{
${ }^{17}$ Las relaciones conmigo y con los otros a partir de Sartre de Ignacio Abello, en particular la tercera sección de la primera parte del libro (La mala fe). "Por lo visto hasta el momento, nos parece que es clara la diferencia entre la concepción freudiana y la de Sartre, especialmente porque para este último no existe una escisión en la estructura psíquica del ser humano, pero además, no pueden relacionarse los conceptos de Sartre y los de Freud, porque los dos están hablando de cosas diferentes, como son esa estructura psíquica donde existe un ello dominante y un yo ignorante de sí, en el caso de Freud, y de una estructura ontológica consciente que tiene la capacidad de ocultarse verdades o de creerse mentiras que le pueden ser útiles a un individuo para la realización de su proyecto, como sucede en el caso de Sartre" (Abello, 2011, p. 64).
} 
intencional que aparece cuando se pierde la conciencia, y que desaparece cuando el agente se hace consiente de la mentira.

Antes señalábamos que la mala fe consistía en la negación de un conocimiento. Así, la mala fe sería un fenómeno intencional y consciente. Ahora, empero, sostenemos que se trata de un fenómeno intencional pero carente de conciencia. ¿Cómo es esto posible, hay una contradicción? Habrá que afinar el enunciado: la mala fe es un fenómeno intencional que consiste en la negación consciente de la libertad del agente, pero ya hecha la negación la conciencia del fenómeno se pierde y tan solo queda la intencionalidad. La mala fe es estructural, esto es una acción que junta el pasado con el futuro del agente.

Por cierto, para quien practica la mala fe, se trata de enmascarar una verdad desagradable o de presentar como verdad un error agradable. La mala fe tiene, pues, en apariencia, la estructura de la mentira. Sólo que $-\mathrm{y}$ esto lo cambia todo - en la mala fe yo mismo me enmascaro la verdad. Así, la dualidad del engañador y del engañado no existe en este caso. La mala fe implica por esencia la unidad de una conciencia (Sartre, 2008, p. 97).

Ante el peso que impone la verdad sobre lo acontecido en el pasado, los agentes se auto engañan para que en el futuro ellos (y los otros) vean sus acciones de cierto modo, librándose así del peso de la verdad. En otras palabras la mala fe es un intento desesperado por sacarse de encima la masa práctico-inerte que nos imponen nuestros actos.

En El ser y la nada Sartre presenta el caso de una muchacha que acude a una primera cita. La mujer sabe de las intenciones que el hombre que le habla abriga respecto de ella. En cierto momento de la conversación él le dice "Siento tanta admiración por usted". La muchacha desarma la frase de su contenido sexual y limita el sentido del enunciado a sus significaciones inmediatas. "El hombre que le habla le parece sincero y respetuoso como la mesa es redonda o cuadrada, como el tapizado de la pared es gris o azul" (Sartre, 2008, p. 105). Ella sabe que en algún momento deberá tomar una decisión y, sin embargo, elude el momento haciendo pasar lo que percibe por otras cosas. La muchacha sabe del deseo que inspira en el hombre, pero el deseo llano la humillaría. Para satisfacerla, comenta Sartre, es menester un sentimiento que se dirija por entero a su persona, es decir, a su libertad. Así como un deseo que a su vez se dirija a su cuerpo en tanto que objeto.

De manera inesperada el hombre le toma la mano.

Este acto de su interlocutor arriesga mudar la situación, provocando una decisión inmediata: abandonar la mano es consentir por sí misma al flirt, es comprometerse; retirarla es romper la armonía tórbida e inestable que constituye el encanto de esa hora (Sartre, 2008, p. 106). 
La muchacha abandona su mano pero no percibe que la abandona. Se ha producido en ella el divorcio entre el alma y el cuerpo, se piensa como pura conciencia; habla de la vida, realiza especulaciones sentimentales, comenta sobre sus sueños y expectativas. Entre tanto "la mano reposa inerte entre las manos cálidas de su pareja, ni consentidora ni resistente: una cosa" (Sartre, 2008, p. 106).

Esta mujer, afirma Sartre, actúa de mala fe. ¿Por qué? El sentido del ser surge en el actuar; cada vez que nos encaminamos en un proyecto apuntamos nuestro ser en determinada dirección. Tal transitar va colocando sobre nuestros hombros un peso. El peso que imponen nuestras decisiones es lo que Sartre llama la masa práctico-inerte. Se trata del peso que, poco a poco, nos va anclando a determinado sentido. Si elijo fumar poco a poco se va colocando sobre mí un peso que me hace más difícil abandonar el hábito. Si voy a una cita y consiento el flirteo, poco a poco se va creando una realidad, con todo su peso, que me va cerrando posibilidades y me hace territorializar con determinadas prácticas.

Lo que hace la muchacha de nuestra historia es tratar de sacarse el peso que le impone la situación en la que se encuentra. Ante la masa practico-inerte del coqueteo ella niega lo que está ocurriendo con el fin de librarse de la situación, de la carga que impone la actitud de su pareja. Se trata de una actitud de mala fe pues consiste en hacer pasar lo que es por lo que no es y lo que no es por lo que es. Tránsito entre la facticidad y la trascendencia.

Ante la frase cuya trascendencia deseante es más que latente, la muchacha decide captar tan solo la facticidad. Ante la toma de su mano, pura facticidad, la mujer abandona su cuerpo y entra en disquisiciones trascendentales. Aunque la muchacha conoce la verdad de la situación, decide auto engañarse a fin de no asumir la responsabilidad que el evento exige. Se trata, en los dos casos, de una negación de lo que se es. Ante la realidad de su trascendencia se concibe como puro cuerpo, y ante la verdad de su cuerpo se piensa como pura trascendencia. Negación de sí, negación de la libertad, negación de sus posibilidades.

Veamos un caso más radical. Tras la captura en territorio argentino de Adolf Eichmann, obersturmbannfürer nazi, se dio inicio el 11 de abril de 1961 en la ciudad de Jerusalén a un juicio fundamental para comprender la historia del holocausto judío. Para los israelíes se trataba de juzgar a un símbolo del nazismo y del racismo que había asesinado aproximadamente a seis millones de judíos europeos. Esta máquina de muerte, que alcanzó su mayor punto en el campo de concentración de Auschwitz, era alimentada por una red ferroviaria que, extendida por toda Europa, se encargaba de transportar a las víctimas: hombres, mujeres y niños que, pocos minutos después de su llegada al campo, eran exterminados en cámaras de gas. Adolf Eichmann era el encargado de coordinar el transporte que realizaban los trenes. 
Cuando a lo largo del juicio se lo interrogaba por su responsabilidad en el holocausto, siempre la evadía. Se presentaba ante todo como un funcionario que se había limitado a cumplir órdenes de sus superiores ${ }^{18}$. Se describía como una pequeña pieza en un engranaje de la gran máquina. Él no se consideraba responsable de la muerte de ningún judío pues su labor, argumentaba, se limitaba al transporte de los trenes. ¿Pero acaso no sabía hacía dónde se dirigían las personas que en sus trenes se movilizaban? ¿Nunca se preguntó por qué los trenes volvían sin personas y sí con las pertenencias de aquellos que antes habían sido transportados? Por su puesto que realizó estas preguntas, -y más importante aún-, está claro que conocía sus respuestas (Eichmann es uno de quienes confirmó la existencia de la conferencia de Wannsee). Las personas que había transportado habían sido asesinadas como parte del macabro plan que los alemanes gustaban en designar eufemísticamente: la solución final. Eichmann es un ejemplo paradigmático de lo que es un hombre de mala fe.

Dos cosas son destacables de las declaraciones de este militar. Él no consideraba sus acciones como propias y además, fuera del ámbito inmediato de la logística del transporte, no preveía las repercusiones de sus actos. Lo que hizo Eichmann a lo largo de su vida y descaradamente durante el juicio fue negar su libertad y enmascarársela en la idea de una máquina que lo determinaba. Su sentir, afirmaba, era como el de Poncio Pilatos: tan solo se limitaba a cumplir el designio de otros más poderosos que él (lavaba sus manos). El resultado: jamás se declaró responsable por lo que hizo aunque sí aceptó los reconocimientos por su labor. Nunca reconoció ni cuidó a los otros que en su actuar afectaba. Eludiendo la libertad tras la idea de un determinismo se puso al servicio de la barbarie y contribuyó al exterminio sistemático de cientos de miles de personas. Eichmann fue un hombre que jugó a cumplir su destino de Caronte.

Lo que nos muestra el caso de Eichmann es cómo un hombre que lee sus actos en el marco de un determinismo metafísico, puede dejar de lado toda consideración ética por la vida del otro. Dado que el acto de mala fe niega el ser del hombre, su realidad, es en consecuencia un acto, como los crímenes nazis, inhumano (antihumano). Quien actúa de mala fe, quien niega su libertad, reniega de su humanidad y deja de lado el originario compromiso que lo llama al reconocimiento y cuidado del prójimo. "Se podría objetar: pero, ipor qué

\footnotetext{
${ }^{18}$ Cierto es que Eichmann se encontraba al interior de un aparato militar burocratizado en el cual debía cumplir órdenes. También es cierto que al interior de estos dispositivos se ha desarrollado un principio de obediencia a la autoridad que hace que personas, que no son malas, sean capaces de realizar actos que en circunstancias no totalitaristas jamás realizarían. El problema en tales contextos no es el de la bondad, sino el del deber. Esto no quiere decir, empero, que tales personas no puedan actuar por fuera de la autoridad. Para una ampliación del tema se puede ir a las siguientes obras: Eichmann en Jerusalén de Hannah Arendt (2013). El efecto lucifer de Philip Zimbardo (2008). Obedience to authority. An experimental view de Stanley Milgram (2009).
} 
no podría elegirse a sí mismo de mala fe? Respondo que no tengo que juzgarlo moralmente, pero defino su mala fe como un error. Así no se puede escapar a un juicio de verdad" (Sartre, 2006, p. 29). Quien actúa de mala fe no actúa racionalmente.

2.2. "Si se me dice "¿y si quiero ser de mala fe?", responderé: "no hay ninguna razón para que no lo sea, pero yo declaro que usted lo es, y que la actitud de estricta coherencia es la actitud de buena fe" $Y$ además puedo formular un juicio moral. [...] Ciertamente la libertad, como definición del hombre, no depende de los demás, pero en cuanto hay compromiso, estoy obligado a querer, al mismo tiempo que mi libertad, la libertad de los otros; no puedo tomar mi libertad como fin si no tomo igualmente la de los otros como fin" (Sartre, 2006, p. 29)

Dado que la condición originaria del hombre es la libertad, quien actúa de mala fe, niega su ser. En tal enmascaramiento no hay asunción óntica de la responsabilidad que implica el actuar, y dado que un tal compromiso abarca a la humanidad entera, quien actúa de mala fe no se preocupa por los otros. Quien actúa de mala fe funda su acción en un error y por tanto podemos juzgarlo lógicamente. Ahora, dado que la no asunción de la libertad compromete el destino de otros entonces podemos realizar, así mismo, un juicio moral: la actitud de estricta coherencia con lo que se es, esto es la actitud que asuma la libertad como fundamento de todo acto, implica una responsabilidad absoluta que supone el cuidado y reconocimiento del prójimo.

¿Por qué no puedo tomar mi libertad como fin si no tomo igualmente la de los otros como fin? La lucha por la libertad es una lucha por el reconocimiento. Se trata de un transitar que persigue el reconocimiento de mis posibilidades existenciales de parte de las otras personas. La lucha por el reconocimiento es una lucha por crear las condiciones adecuadas para la materialización del poder ser. Este reconocimiento que busco solamente será posible en la medida en que yo también reconozca las posibilidades existenciales de los otros, pues de lo contrario dado que toda relación con el prójimo es recíproca y mutable, el no reconocimiento del prójimo es un no reconocimiento de mí ser. De la comprensión de estas características atribuibles a toda relación con el otro se derivan dos principios morales fundamentales: solo puedo querer para mí lo que quiero para todos los hombres; (y su paralelo) no puedo querer para los otros lo que no quiero para mí. 
"Todo lo que vale para mi vale para el prójimo. Mientras yo intento liberarme del dominio del prójimo, el prójimo intenta liberarse del mío; mientras procuro someter al prójimo, el prójimo procura someterme" (Sartre, 2008, p. 498). Lo que ocurre es que yo tan solo puedo ser lo que soy a ojos del otro, y si yo no reconozco lo que el otro es, no puedo esperar que el prójimo me reconozca de la manera en que yo quiero ser reconocido.

La relación con el otro, señala Sartre, se construye sobre el problema de la mirada. El ser-con es fundamentalmente un ser-en-la-mirada-del-otro. El prójimo es ante todo alguien que me mira y que en su mirada me captura y configura con su juicio. El otro me mira y roba algo de mí, algo que hace suyo y con lo cual construye el juicio: "usted es X". Es en virtud del juicio del otro que yo puedo ser. Veamos un ejemplo. Si soy homosexual y me encuentro en una sociedad cuya mirada no quiere reconocer lo que soy, entonces no puedo ser como me quiero. No es que deje de ser homosexual y transite, en consecuencia, hacia la heterosexualidad. Lo que ocurre es que al no ser reconocido como lo que soy me encontraré en una sociedad que no permite la materialización de mis opciones, y en consecuencia, no podré ser como me quiero. Debido a que el juicio del otro configura mi realidad y mis posibilidades es que Sartre señala que "el infierno son los Demás" (Sartre, 1948a, p. 107).

Tal enunciado no quiere decir que las relaciones con el prójimo estén siempre condenadas al mal, o constituyan la materialización de una prohibición. Quiere decir que si nuestras relaciones son negativas entonces el prójimo ha de ser el infierno. Y es que como se señala en seguida:

los otros son en el fondo lo que hay de más importante en nosotros mismos, para el conocimiento de nosotros mismos. Cuando pensamos en nosotros, cuando ensayamos conocernos, en realidad utilizamos conocimientos que los otros tienen de nosotros, es decir, que juzgamos con los medios que los otros nos han dado para juzgarnos" (Abello, 2011, p. 192).

Si el juicio del otro no me hace justicia entonces estoy en el infierno; si mi juicio no hace justicia a lo que el otro es entonces coloco al prójimo en el infierno. Que el juicio del otro haga justicia con lo que soy, quiere decir que sea un juicio que reconozca mi libertad. Reconocer al otro quiere decir dar cuenta de su libertad en mi juicio. Tal es un principio moral que se deriva de la teoría de la acción existencial al ser asumido el compromiso que la libertad implica. Lo que nos está diciendo Sartre es que lo que cada cual es, aunque es su responsabilidad, nos compete a todos. Lo que yo soy es mi responsabilidad, pero a su vez le compete al otro, pues es él con su juicio el que me permite ser. Lo que es el otro es responsabilidad suya, pero también me compete, pues soy yo con mi juicio el que le permito ser:

Así, tengo la comprensión de esta estructura ontológica: soy responsable de 
mi ser-para-otro, pero no su fundamento; mi ser-para-otro se me aparece, pues, en forma de algo dado y contingente de que, sin embargo, soy responsable, y el prójimo funda mi ser en tanto que este ser es en la forma del "hay"; pero no es él el responsable aunque lo funde en plena libertad, en y por su libre trascendencia (Sartre, 2008, p. 499).

¿En qué sentido no soy responsable de lo que el otro es? Cuando Sartre señala que yo no soy responsable por lo que el otro es quiere decir que no es sobre mí que se coloca el peso de la masa práctico-inerte que los actos del otro generan. Yo no puedo asumir tal peso pues finalmente cada acto del otro es desencadenado por su subjetividad y nunca en virtud de un determinismo que yo le impongo. Pero esto no quiere decir que yo no deba declararme responsable del otro en virtud de la manera como lo afectan mis actos y juicios. Todo lo contrario, como lo que yo hago y digo configura un mundo que posibilita o restringe las posibilidades del otro: yo soy responsable por tal afectación. Yo no soy responsable de la homosexualidad del otro pero sí de promover una sociedad homofóbica o inclusiva que aniquile o deje ser al prójimo. Yo no soy responsable por lo que el otro es, pero sí soy responsable de dejar -o no- ser al otro.

Lo que se deriva de la teoría de la acción existencial, en un marco ético, es que si yo asumo mi libertad habré de luchar por la libertad del otro y, en consecuencia, mis actos y juicios tratarán de promover su realización tal y como él se quiera. Del existencialismo se sigue un principio político: debemos crear sociedades que reconozcan y promuevan la otredad. No hacerlo es negar lo que somos (libertad). No hacerlo es actuar de mala fe. No cuidar y reconocer al otro es actuar de manera inhumana. "[...] Con ocasión de mi concreto, padecido y sentido experimentar al otro, quiero incorporar en mí a ese otro concreto como realidad absoluta en su alteridad" (Sartre, 2008, p. 500).

2.3. "Por el yo pienso, contrariamente a la filosofía de Kant, nos captamos a nosotros mismos frente al otro, $y$ el otro es tan cierto para nosotros como nosotros mismos. Así, el hombre que se capta directamente por el cogito, descubre también a todos los otros y los descubre como la condición de su existencia. Se da cuenta que no puede ser nada (en el sentido que se dice que se es espiritual, malo - celoso), salvo que los otros lo reconozcan por tal. Para obtener una verdad cualquiera sobre mí, es necesario que pase por otro" (Sarte, 2006, p. 25)

La asunción de la libertad propia implica la lucha por el reconocimiento de la libertad de los demás. Esa lucha no se desarrolla tan solo en un ámbito público sino que permea todas las esferas de la vida privada. La lucha por la libertad del otro debemos realizarla, en primera instancia, en nosotros mismos; se trata de 
una lucha contra los prejuicios que hacen que nuestros juicios sobre el otro no lo reconozcan impidiéndole ser tal y como él se quiere. Una tal labor supone, ante todo, la conciencia sobre el poder de nuestros juicios. Cuando nombramos algo o alguien no solamente le atribuimos un término para designarlo, sino que lo insertamos en una serie de categorías que se convierten en el fundamento de su experiencia posible. Si decimos "ese hombre es un esclavo y debe ser tratado como tal", en un plano óntico no solo lo hemos nombrado de cierta manera, sino que también hemos transformado su vida: ese hombre sufrirá la opresión de otros hombres y no podrá manifestar su libertad.

Es lo que Sartre muestra en su obra de teatro La mujerzuela respetuosa. En ella un hombre, un negro, es perseguido por el grueso de una ciudad en el sur de los Estados Unidos. Lo acusan de haber violado a una mujer blanca en el tren. Se trata de un crimen infundado que se alimenta por el odio racial. A pesar de que el hombre no ha hecho nada, el juicio histórico de los blancos, quienes afirman que "un negro siempre ha hecho algo", ha permeado tan fuerte en él que no puede hacerse como se quiere y además se siente culpable:

(Hurga en un cajón y saca un revólver)

EI NEGRO. - ¿Qué quiere usted hacer señora?

LIZZIE. - Voy a abrirles la puerta y les rogaré que entren. Hace veinticinco años que me engatusan con sus ancianas madres de cabellos blancos y los héroes de la guerra y la Nación americana. Pero he comprendido. No me estafarán hasta el final. Abriré la puerta y les diré. "Está ahí. Está ahí, pero juro que no hizo nada; me han sonsacado un falso testimonio. Juro por Dios que no hizo nada".

EL NEGRO. - No le creerán.

LIZZIE. - Es posible. Es posible que no me crean; entonces los apuntarás con el revólver, y si no se van, dispararás.

EL NEGRO. - Vendrán otros.

LIZZIE. - Dispararás también a los otros. Y si ves al hijo del senador, trata de no errar, porque él fue quien lo tramó todo. Estamos acorralados, ¿no? $\mathrm{Y}$ de todos modos, es nuestra última historia porque te aseguro que si te encuentran en mi casa no doy un centavo por mi piel. Por lo tanto, es preferible reventar en numerosa compañía. (Le tiende el revolver) iTómalo! Te digo que lo tomes.

EL NEGRO. - No puedo, señora.

LIZZIE. - ¿Qué?

EL NEGRO. - No puedo disparar contra los blancos.

LIZZIE. - iDe veras! Ellos se enfadarán.

EL NEGRO. - Son blancos, señora.

LIZZIE. - ¿Y qué? ¿Por qué son blancos tienen el derecho de sangrarte como a un cerdo?

EL NEGRO. - Son blancos. 
LIZZIE. - ilmbécil! Mira, te pareces a mí, eres tan bobalicón como yo. En fin, si todo el mundo está de acuerdo...

[...]

LIZZIE. - Puedes salir. (EI NEGRO sale, se arrodilla, y le besa el ruedo del vestido.) Te dije que no me tocaras. (Lo mira) Con todo y has de ser un tipo especial para tener a toda la ciudad detrás de ti.

EL NEGRO. - No hice nada, señora, usted bien lo sabe.

LIZZIE. - Dicen que un negro siempre ha hecho algo

EL NEGRO. - Nunca hice nada. Nunca. Nunca.

LIZZIE (se pasa la mano por la frente). - Ya no sé qué pensar. (Una pausa.)

Con todo, una ciudad entera no puede estar completamente equivocada.

(Una pausa) iDemonio! No comprendo nada.

EL NEGRO. - Es así, señora. Siempre es así con los blancos.

LIZZIE. - ¿Tú también te sientes culpable?

EL NEGRO. - Sí, señora.

LIZZIE. - ¿Y sin embargo no has hecho nada?

EL NEGRO. - No, señora.

LIZZIE. - ¿Pero qué tienen entonces para que uno está siempre de su parte?

EL NEGRO. - Son blancos (Sarte, 2006, p. 25).

Así como toda verdad sobre mí pasa por el otro, toda verdad sobre el prójimo pasa por mí. Si yo no asumo mi libertad y la responsabilidad absoluta que ella implica no cuidaré del otro en mi juicio y seré como los blancos de la obra que, desconociendo la otredad, no ven problema en asesinar a aquél que es diferente.

Pero asumir la responsabilidad por el otro no sólo es reconocerlo en mi juicio, sino también cuidarlo con mis actos, esto es potenciar su libertad con mis acciones. Cuidar de alguien no es interponer límites entre él y el mundo de suerte que el sujeto se aislé de aquello que pueda dañarlo. Cuidar a alguien es promover la instauración de condiciones materiales ideales para la efectiva realización de la libertad del sujeto. Y es que si bien la condena a la libertad es inalienable, lo cierto es que en un marco óntico existen contextos que facilitan o dificultan el ejercicio de la libertad. Cuidar del prójimo es cuidar su libertad con acciones que promuevan un contexto de apertura para la subjetivación de la existencia.

Tal es un principio que se juega en ámbitos públicos y privados; las prácticas propias de cada territorio no son, sin embargo, sintetizables como teoremas de la teoría. Una tal suposición traicionaría las pretensiones historicistas de la doctrina y supondrían, más bien, un síntoma de totalitarismo. Son tales prácticas las que deben ser estudiadas en contextos locales o en el marco de nuestras instituciones democráticas. Una tal labor aunque absolutamente necesaria supera, sin embargo, los límites de este texto. Aun así un primer paso ha sido dado, hablo de la conciencia sobre lo que constituye una dimensión de la acción responsable: 
esto es el cuidado y reconocimiento del prójimo. Las prácticas propias de tal tránsito han de ser descubiertas en el actuar de los hombres y mujeres que, asumiendo la responsabilidad que su inalienable libertad supone, saquen las últimas consecuencias del compromiso existencial $\Phi$

\section{REFERENCIAS}

Abbagnano, N. (1997). Introducción al existencialismo. Colombia: Brevarios. Fondo de Cultura Económica.

Abello, I. (2011). Las relaciones conmigo y con los otros a partir de Sartre. Bogotá: Uniandes.

Adorno, T. (1984). Dialéctica negativa. Madrid: Taurus.

Allison, H. (1992). El idealismo trascendental de Kant. Una interpretación y defensa. Barcelona: Anthropos.

Anscombe, G. E. (1991). Intención. Barcelona: Paidós.

Arendt, H. (2013). Eichmaan en Jerusalén. Bogotá: Debolsillo .

Davidson, D. (1995). Ensayos sobre acciones y sucesos. Barcelona: Crítica. Grijalbo Mondadori.

De Gamboa, C. (2005). El carácter empírico e inteligible de las acciones humanas. En W. Herrera, \& C. De Gamboa, Kant: defensa y límites de la razón (págs. 83-98). Colombia: Universidad del Rosario.

Heidegger, M. (2008). El ser y el tiempo. México D.F.: Fondo de Cultura Económica. Kant, I. (1978). Crítica de la razón pura. Madrid: Alfaguara.

Kant, I. (1985). ¿Qué es la ilustración? En I. Kant, Filosofía de la historia (págs. 2538). México: Fondo de Cultura Económica.

Milgram, S. (2009). Obedience to authority. An experimental view. usa: Perennial.

Popper, K. (1986). El universo abierto. Un argumento en favor del indeterminismo. Madrid: Tecnos.

Sartre, J. P. (1948a). A puerta cerrada. En J. P. Sartre, Obras. Teatro y estudios literarios (págs. 73-108). Buenos Aires: Losada. 
Sartre, J. P. (1948b). La mujerzuela respetuosa . En J. P. Sartre, Obras. Teatro y estudios literarios (págs. 159-186). Buenos Aires: Losada.

Sartre, J. P. (2006). El existencialismo es un humanismo. México: Exodo.

Sartre, J. P. (2008). El ser y la nada. Buenos Aires: Losada.

Zimbardo, P. (2008). El efecto lucifer: el porque de la maldad. Barcelona: Paidós. 